Doctor en Filología Hispánica. Titular de Literatura Española en la Universidad de Alicante. Autor de libros de poesía y traducciones en verso. Ensayista (Contramáscaras). Editor de Garcilaso, Iriarte, J. L. Hidalgo, A. Gamoneda. Antólogo de poesía clásica (Poesía del Renacimiento) y contemporánea (1939-1975: Antología de

\title{
«ESPIRAL», DE FÉLIX GRANDE: UNA LETANÍA NERUDIANA PARA VIAJAR POR LA HISTORIA
} poesía española y Poetas españoles de los cincuenta). A la lírica del XX ha dedicado, además, los libros La llama y la ceniza (Introducción a la poesía de Claudio Rodríguez), La lira de Arión (De poesía y poetas españoles del siglo XX), Musa del 68 y De manantial sereno (Estudios de lírica contemporánea).

\author{
Ángel L. Prieto de PaUla
}

En 1971 publicó Félix Grande (Mérida, 1937) el cuaderno de prosas poéticas Puedo escribir los versos más tristes esta noche, cuyo título está extraído del conocidísimo poema vigésimo del libro nerudiano Veinte poemas de amor y una canción desesperada. Esta obra de Grande se escribió entre 1967 y 1969, y se cierra con una composición titulada «Espiral», la única en verso de todo el conjunto ${ }^{1}$.

No es este librito uno de los más valorados de su autor, en parte por tratarse de una colección mayoritariamente prosística, más difícil por tanto de integrar en su sistema poético regular; pero también porque resultó oscurecido por la publicación, ese mismo año, de otras dos obras. Una de ellas es Taranto (Homenaje a César Vallejo), escrita diez años atrás, donde la presencia vallejiana alcanza el mayor relieve; algo nada extraño si sabemos que el libro fue concebido, en las palabras del propio autor, como un plagio voluntario de César Vallejo, al margen de que a lo largo de toda su obra se perciba el gran influjo del peruano, muy notorio en las peculiares creaciones léxicas, en las compulsiones y quiebras sintácticas, en la presentación radical, trémula y desparramada de sentimientos sin contención ni cautela. El otro libro que vio la luz ese año es la primera edición de su por entonces poesía completa, Biografía, luego reeditado en 1986 ya con la incorporación de inéditos y poemarios publicados tras 1971. En esa su inicial salida, Biografía contenía, además de los primeros títulos de Grande - Las piedras, 1964, y Música amenazada, 1966-, uno de los dos libros que forman el axis estético del autor: Blanco spirituals, aparecido en 1967. Con él se introducían en la poesía española los estímulos psíquicos y algunos procedimientos rítmicos del espiritual negroamericano $y$, en general, del jazz ${ }^{2}$. No deben, sin embargo, desdeñarse en la constitución estética de este libro ciertas esencias del expresionismo - del llamado por lo común, con escasa precisión crítica, tremendista-, más bien como desarrollo de la propia tesitura poética del autor que como mimetismo respecto a sus presuntos modelos; y asimismo del socialrealismo, cuando éste había entrado en una franca e irremisible declinación muy cercana a su desaparición efectiva. La influencia del jazz, visible sobre todo en algunos poemas basados en el verbalismo fluyente según ciertos esquemas léxica y musicalmente reiterativos, no se da sólo en las formas, sino también en los temas y en el tono. A este respecto, en la poética de Félix Grande han influido tanto el jazz como el flamenco, de cuya historia y caracteres es uno de los máximos especialistas, toda vez que éste es una manifestación correlativa a los cánticos de la negritud norteamericana. La publicación de Blanco spirituals fue en parte negativa para el autor, quien, más bien que apabullado por la relativa notoriedad adquirida, se sintió instalado en una poética sistemática en la cual no se reconocía del todo y donde no quería quedar encerrado. Según sus propias palabras, la nombradía que le granjeó ese libro, y el peligro de obturación de otros caminos poéticos aun antes de su exploración, supuso la caída del poeta en un desconcierto respecto a la creación que lo condujo «hasta
1

Todas las consideraciones y referencias a la obra del autor las hago por Biografía. Poesía completa (1958-1984), Barcelona, Anthropos, $1989\left(1^{\mathrm{a}} \mathrm{ed}\right.$. en Anthropos: 1986). El poema que analizo, y que reproduzco al final de mi artículo, figura en pp. 290-292.

2

Antonio Gamoneda escribió también por esos años, entre 1961 y 1966, Blues castellano, donde se percibe netamente el influjo del jazz, y, de manera más acusada que en Félix Grande, un afán de reproducir las salmodias cansinas y lacerantes de los espirituales negros. El libro de Gamoneda, que asimismo mostraba influencias evidentes del turco Nazim Hikmet y de la poesía social española, no pudo publicarse entonces. Apareció muchos años después, en 1982, cuando había pasado completamente su oportunidad de romper moldes y de abrir estelas (una condena que no turo que cumplir Félix Grande con el suyo).

\footnotetext{
«Espiral», de Félix Grande: una letanía nerudiana para viajar por la historia
}

ÁNGEL L. PRIETO DE PAULA 
4 Ibid.

\section{5}

"Apenas comenzado ese ejercicio de escritura, y como si la vida fuese - como a veces lo esmisteriosamente cómplice de los hombres, me sucedió una historia a la que creo que puedo denominar espléndida y terrible. Una historia de amor prohibido. Ese suceso (junto con sus antecedentes psicológicos y sus consecuencias vitales) fue tirando del libro, y lo que había empezado siendo un ejercicio de redacción, una aventura de humildad y de astucia poéticas, y la búsqueda de un tono expresivo, acabó siendo una larga metáfora de la nostalgia, la cólera y la desobediencia, un acto de gracias al sentido más misterioso, opulento y aterrador, el sentido del tacto, $y$ un enfrentamiento contra los administradores y los censores del placer» (ibid., p. 14).

6

Ibid., p. 13.

«Espiral», de Félix Grande: una letanía nerudiana para viajar por la historia

ÁNGEL L. PRIETO DE PAULA un silencio al que sólo pude abolir con algo de humildad y coraje, dones que tanto se parecen» ${ }^{3}$. Al notarse amenazado por las expectativas creadas por ese libro, decidió desatenderlas: «De aquella incertidumbre, de aquel desasosiego - quizá pueda decir: de aquella angustia-, extraje fuerza para desobedecer una vez más: ahora, a mis nuevos lectores. Y de aquel acto de desobediencia obtuve un nuevo libro y el principio de otro. El nuevo libro acabaría llamándose Puedo escribir los versos más tristes esta noche» ${ }^{4}$. Enseguida volveremos a él.

El segundo libro aludido, cuyo inicio se debe a esa crisis creativa, es Las rubáiyátas de Horacio Martín (1978), a mi juicio una obra mayor del último cuarto del siglo XX. Con ella ingresa Félix Grande en la senda de los heterónimos, tan cara a Antonio Machado, uno de los dos autores fijos de su devocionario estético, en la confesión del propio poeta; el otro, ya se ha dicho, es César Vallejo. Pero esto en nada atenúa el realismo psíquico que lo caracteriza. En un principio, el propósito autorial era producir unos poemas descarnados y enjutos, reducidos los desbordamientos léxicos de que había hecho gala en Blanco spirituals, para liberarse de una plétora verbal que comenzaba a pesarle; pero esa propuesta de retórica sin retórica pronto fue dando cuerpo a un conjunto de poemas extraordinarios que ensamblaron los episodios de una apasionada historia amorosa expresable tan sólo, por su rara intensidad y el carácter prohibido de ese amor ${ }^{5}$, mediante la tormenta de la desazón erótica, las pulsiones del deseo irrefrenable y la indisciplina soberbia de un sentimiento que choca, hasta quedar destrozado, contra los muros de la convención y las componendas de la sociedad.

Pero volvamos al poemario donde está incluida la composición que nos concierne ahora. En el «Prólogo» con que encabeza Biografía, comenta de él su autor, además de las circunstancias de su crisis, que siendo «acaso el más nocturno de mis libros, me ayudó a sentirme de nuevo extraviado en las galerías de mi alma, por usar la expresión machadiana» ${ }^{6}$. Poca cosa, si esperábamos una precisión estética respecto al conjunto de su obra; aunque suficiente si nos conformamos con saber que el libro altera los cursos de la estética que había ido forjando, y que en muy buena medida fue una experimentación respecto a la experimentación anterior, la de Blanco spirituals, ya consolidada en sistema. Omitiremos otras consideraciones sobre él, aunque bien las merece, para limitarnos al poema «Espiral», una de las más hermosas, intensas y fragorosas composiciones poéticas del tiempo histórico de Félix Grande.

«Espiral» es un poema de noventa versos de medida diversa y sin rima, agrupados en varias series de distinta extensión, salvedad hecha de los cuatro versos últimos, que aparecen como entidades autónomas y solitarias, lascas de un discurso del que al final se han desprendido en el vertiginoso zarandeo temático de la composición. En ese zarandeo, del que no están ausentes las iteraciones jazzísticas a que antes me he referido, intervienen dos factores de gran interés rítmico. $\mathrm{El}$ primero tiene que ver con el término de muchas de las series, rematadas con "Puedo escribir los versos más tristes esta noche», primero y último verso, además, de la composición, toda ella abrazada por esa invocación a la tristeza. La monodia subyugante del alejandrino nerudiano atrae todos los otros componentes temáticos, todas las otras incitaciones tonales, hacia el sonsonete recurrente de esta expresión plagada de una melancolía cósmica. El segundo factor rítmico es relativo a la conexión entre la música y el sentido. Aunque no puede hablarse de un rígido sistema esticomítico, en el que las unidades semánticas quedaran encajonadas en versos cerrados, sin embargo existe una tendencia evidente hacia ello: los versos, rara vez puntuados en su interior y nunca en su final, propenden a identificarse con segmentos verbales de sentido completo, lo que incrementa el pálpito machacón de las iteraciones, en este caso estructurales (vv. 46-50):

Mi hija golpea en la puerta

escucho el tronco hueco de mis antepasados

La cena huele a astillas de megaterio mudo

La mesa limpia tiene lobos

El reloj marca un cero deforme

O, poco más abajo (vv. 58-63):

El reloj de pared marca las nueve y media Sube desde la calle el sonido del tráfico Un perro allá en el pueblo ladra Un obús silba allá en la guerra Allá por todas partes hay miedo sangre cálices miembros rotos fósforo ardiendo

El poema contiene una historia personal imbricada en una historia universal reducida 
a muy pocos episodios vinculados directamente o no a la existencia del autor. Su construcción es de tipo acumulativo, en disposición no sucesiva cronológicamente. Su nervadura presenta una serie de irradiaciones atropelladas, con vocación de simultaneidad (aunque no del todo simultáneas en tanto que lo impide el discurso poético). El centro desde el que parten tales irradiaciones es un sujeto coincidente con el poeta que registra por escrito las incitaciones de su cerebro. El ejercicio de esa escritura versa sobre el sentido de la historia y la consideración del yo, desembocadura en que han venido a parar acontecimientos de la humanidad desde los tiempos ancestrales ${ }^{7}$. Importa mucho precisar la identificación entre poeta y sujeto: el axioma pessoano de que «el poeta es un fingidor» nada dice en realidad contra esta identificación, pues ese fingimiento consiste en la adopción de las vestiduras retóricas por las que el poeta «llega a fingir que es dolor / el dolor que de veras siente» (la cursiva es mía); y, como en el poema de Ángel González referido en nota, existen alusiones autobiográficas inequívocas que acotan esta identificación escasamente posmoderna, si no bastara para indicarlo el mismo título - Biografíade la obra completa del poeta. Ese punto subjetivo de partida —el autor, la voz poemática- se ubica en un tiempo histórico: «esta noche», según reza la letanía; más en concreto las nueve y media de la noche de un día de 1969, momento de la escritura del poema o, cuando menos, de la constitución psíquica del pensamiento que se vierte en él. Y ello acaece en un lugar específico: el cuarto de su casa en que se encuentra.

Según antes se ha sugerido, domina una construcción yuxtapositiva, como es propio de un texto donde el pensar escalonado es sustituido por la mostración de estampas que contunden una tras otra en la sensibilidad del lector, y cuya contigüidad sintagmática provoca en el receptor una impresión de solapamiento. Esta yuxtaposición está lograda mediante dos recursos fundamentalmente. Por un lado, la disposición casi paralelística de estructuras oracionales muy simples y semejantes entre sí; basta con observar los comienzos de verso en una de las series reproducida atrás (vv. 46-50). La predominancia del presente de indicativo, que muchas veces se mantiene con independencia de los distintos tiempos histó- ricos referidos ( Hace un momento tengo quince años», v. 37), promueve una convergencia de todos los segmentos temporales agolpados en el aquí y el ahora. El otro recurso es la escasez de conectores sintácticos que establezcan los nexos gramaticales $y$, por tanto, la jerarquía oracional y las relaciones de dependencia, lo cual, unido a la ausencia de puntuación, propicia la concurrencia sensitiva de aconteceres argumentalmente distintos y cronológicamente alejados; nótese en la siguiente serie (vv. 51-57):

Hace un momento mamá y papá cenaban

hablaban se besaban

creyendo que yo estaba dormido

Papá emigra del pueblo para hacernos llegar

un poco de carne de bestia

Mamá chupa un tendón monstruoso y llora sola

Puedo escribir los versos más tristes esta noche

Esta idea de concurrencia está intensificada por la repetición de ciertas fórmulas como la locución temporal del inicio de la serie anterior («Hace un momento»); he aquí los comienzos de algunas de estas tiradas:

Hace un momento mis antepasados

Hace un momento tengo quince años

Hace un momento mamá y papá cenaban

Hace un instante me han comprado un cuaderno

Engarzados por el monocorde y obsesivo verso de Neruda, los estratos de la historia se superponen sin argamasa sintáctica. Un solo elemento formulario basta para marcar el salto de una época a otra: el reloj de pared que, como el catalejo de "Una ciudad y un balcón» (Azorín, Castilla), señala no tanto los tránsitos como la instalación en cada una de las estancias cronológicas:

$$
\begin{aligned}
& \text { El reloj de pared } \\
& \text { marca mil novecientos } \\
& \text { sesenta y nueve... }
\end{aligned}
$$

El reloj marca mil novecientos treinta y siete (v. 8)

El reloj de pared marca mil novecientos cuarenta y cinco...

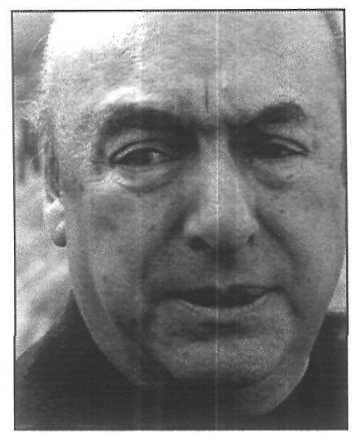

Pablo Neruda.

7

El poema inicial del libro de Ángel González Áspero mundo (1956), que comienza con el verso «Para que yo me llame Ángel González», presenta también a un sujeto identificado netamente con el poeta, según lo denota la autonominación del primer verso, como último eslabón de una cadena que ha ido formándose al discurrir de los siglos y las generaciones: «Para que yo me llame Ángel González, / para que mi ser pese sobre el suelo, / fue necesario un ancho espacio / y un largo tiempo: / hombres de todo mar $y$ toda tierra, / fértiles vientres de mujer, y cuerpos / y más cuerpos, fundiéndose incesantes / en otro cuerpo nuevo. / Solsticios y equinoccios alumbraron / con su cambiante luz, su vario cielo, / el viaje milenario de mi carne / trepando por los siglos y los huesos»... Como en el caso de Félix Grande, hay un afán de situar una individualidad irrestricta en una serie histórica acumulativa que, en cierto sentido, deshace el dilema planteado en las inacabables discusiones en torno a la primacía de lo personal o lo colectivo durante la dominación del socialrealismo.

\footnotetext{
«Espiral», de Félix Grande: una letanía nerudiana para viajar por la historia ÁNGEL L. PRIETO DE PAULA
} 


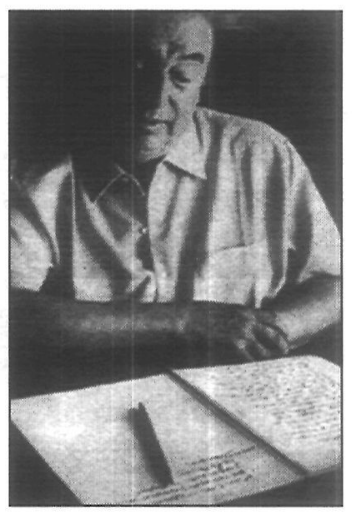

Pablo Neruda.

8

El verso "Cae la primera bomba nuclear» está precedido por otros que recogen una estampa circular: un tirano prehistórico contempla a un niño que mama en la teta de su madre "para esperar a su propio asesino». El tiempo de la inocencia es tiempo de espera para derrocar y para ser derrocado. Los sillares de la historia propician una lectura no sólo en sucesión sin en concarenación de hechos - aunque falten los marcadores gramaticales que pudieran indicarlo irrebatiblemente-, de manera que la bomba nuclear se oye como resultado y quintaesencia de la crueldad previa y universal.

«Espiral», de Félix Grande: una letanía nerudiana para viajar por la historia

ÁNGEL L. PRIETO DE PAULA
El reloj de pared marca las nueve y media

La exposición poética sólo al principio se despliega en secuencias temporales relativamente unitarias. En la serie primera, los tiempos de la guerra en 1937, apenas nacido el sujeto, pueden considerarse una remembranza retrospectiva realizada desde el presente de la escritura. Sin embargo, a partir de la tercera serie ( $E$ El reloj de pared marca mil novecientos / cuarenta y cinco») se enredan las fechas y los acaeceres en cada una de ellas, de manera que los distintos momentos históricos se cruzan y arraciman, y determinados elementos recurrentes se hacen comunes a todos esos tiempos: el reloj de pared, el tronco hueco con que se comunicaban con precariedad los antepasados prehistóricos (los cuales conectan no sólo con el sujeto, sino con su hija, que golpea la puerta para avisar a su padre que la cena está servida). No es extraño que hacia el final del poema se hayan borrado todas las distancias entre pasado y presente, enlazados por el sonido que percute en los oídos y en la sensibilidad del autor, a la vez ascendiente prehistórico en busca del lenguaje y escritor en busca de palabras: «Soy un antepasado golpeando un tronco hueco» (v. 82).

Algunos tiempos de la vida personal o histórica están claros: 1969 es el presente en el que el poeta escribe y efectúa el ejercicio rememorativo e imaginativo, cuando tiene los treinta y dos años que han marcado su rostro según se refleja en el cristal del reloj (vv. 72-74); 1937 es el año de su nacimiento, y es también año de una dolorosa guerra visible en la imagen de su madre corriendo con él en brazos para ponerlo a resguardo de las bombas; 1945 representa, ya, una primera salida del círculo de lo personal, como en una comunión de dolores, con la alusión al lanzamiento de la bomba de Hiroshima; las nueve y media es la hora de la escritura o de la reflexión, cuando la hija lo saca del ensimismamiento. Otras referencias al reloj (v. 50) no son adscribibles a un tiempo convencional, y aluden probablemente a la distorsión de la figura del reloj en la percepción del sujeto por la confluencia en simultaneidad psíquica de esta summa vite, no sólo del hombre que escribe, sino de toda la humanidad precedente.
En ese nudo de la historia, coincidente con el presente de la escritura, se concentran los momentos vividos o no por él, pero, en cualquier caso, con fuerte incidencia en él: los bombardeos de la guerra civil; los esbozos de un lenguaje no proposicional por parte de los integrantes de la horda troglodítica, todavía pegada a los primordia que constituyeron el mundo («borracha de materia original», p. 15); el lanzamiento de la primera bomba nuclear, resumen de una crueldad universal en la que todos son víctimas y verdugos y de nuevo víctimas ${ }^{8}$; la revelación del amor a los quince años, pareja al descubrimiento de la muerte ( Sigo haciendo el amor gimiendo hiriendo / mientras mueren mis familiares», vv. 40-41); la reunión fuera del tiempo sucesivo de padres e hijos, ancestros y descendientes («Papá emigra del pueblo», v. 54; «Mi hija golpea en la puerta», v. 43; «Vienen mis nietos a llorar», v. 77), en una recapitulación en la que concuerdan avances y retrocesos... El llanto parece ser el denominador común de esta vorágine, de esta destrucción regenerativa $o$, tanto monta, de esta regeneración funeral que llamea en un calidoscopio: "Allá por todas partes hay miedo sangre cálices / miembros rotos fósforo ardiendo» (vv. 62-63).

Por lo visto, los distintos momentos cronológicos y los diversos componentes del poema han sido alcanzados desde el punto irradiador donde se situaba el poeta. El dibujo de los movimientos de la acción es, mejor que la espiral referida en el título, el de un centro que primero se abre en una diáspora (el poeta, radicado en el presente, hacia el pasado prehistórico, hacia su niñez, hacia su adolescencia, hacia sus nietos futuros) cuya confusión produce una extraña sensación alucinatoria, y que al final recupera un talante unitivo, cuando «La materia total gira enloquece» (v. 87) en una regresión hasta la convergencia última en el mismo lugar del que partió todo. En tal punto, el hombre que piensa y escribe lleva sobre los hombros el peso de toda la humanidad, la microhistoria de su vida contiene vestigios de historias añejas y redivivas, y en la llamada de la hija a la puerta se oyen, también, los golpes de los antepasados en el tronco desde el que se emitía noticia de los dolores ocurridos y por ocurrir. Engastándolo todo, la terebrante letanía nerudiana resuena como un tam-tam insomne que va pautando con su congoja la noche de la escritura. 


\section{ANEXO}

\section{ESPIRAL}

Puedo escribir los versos más tristes esta noche

El reloj de pared

marca mil novecientos

sesenta y nueve. Hace un instante

5 mamá viene corriendo por las calles

en busca de un refugio

Contra las bombas me oculta en sus brazos

El reloj marca mil novecientos treinta y siete

Puedo escribir los versos más tristes esta noche

10 Hace un momento mis antepasados

comenzaban a golpear un tronco hueco

para comunicarse con los más próximos lejanos

Sale la luna y toda la horda

se siente rodeada de tigres

15 borracha de materia original

Examinan el mundo vacío

y sienten que les falta el lenguaje

Golpean sobre un tronco

arrancando de él sílabas enigmáticas

20 religiones extrañas

conocimientos ilegibles

extenuantes soberbias

premoniciones pavorosas

que se habrán de cumplir una por una

25 Puedo escribir los versos más tristes esta noche

El reloj de pared marca mil novecientos

cuarenta y cinco. Suben

las sombras arañando el tiempo

Un tirano de la horda

30 despedaza la carne de un venado

El salvaje que habrá de asesinarlo

para esperar a su propio asesino

mama en la teta de su madre

El tirano lo mira alimentarse

35 No hay escena más plácida más horrenda que ésta

Cae la primera bomba nuclear

Hace un momento tengo quince años

Sube a mi piel el secreto más honesto del mundo

muerdo la carne de una vecina silenciosa

40 Sigo haciendo el amor gimiendo hiriendo

mientras mueren mis familiares

Puedo escribir los versos más tristes esta noche

Mi hija golpea en la puerta

Con su idioma inicial repentino

45 me recuerda que debo ir a la cena

Mi hija golpea en la puerta escucho el tronco hueco de mis antepasados

La cena huele a astillas de megaterio mudo

La mesa limpia tiene lobos

50 El reloj marca un cero deforme

Hace un momento mamá y papá cenaban

hablaban se besaban

creyendo que yo estaba dormido

Papá emigra del pueblo para hacernos llegar

55 un poco de carne de bestia

Mamá chupa un tendón monstruoso y llora sola

Puedo escribir los versos más tristes esta noche

El reloj de pared marca las nueve y media

Sube desde la calle el sonido del tráfico

60 Un perro allá en el pueblo ladra

Un obús silba allá en la guerra

Allá por todas partes hay miedo sangre cálices

miembros rotos fósforo ardiendo

Los ojos de un cadáver anónimo

65 ruedan al suelo y miran con misericordia:

ven a la horda pidiendo socorro

mediante un tronco hueco

Mi hija golpea en la puerta

Puedo escribir los versos más tristes esta noche

70 Hace un instante me han comprado un cuaderno un portafolios un papel de calco

$Y$ en ese cristal que preserva

las manecillas del reloj

miro mi cara de treinta y dos años

75 Sigo mirando hacia ese rostro antiguo

Sin apartar la vista mi cabeza se apaga

Vienen mis nietos a llorar. Se van

Puedo escribir los versos más tristes esta noche

Miro el reloj con amor con espanto

80 con amor con espanto

Miedo amor corazón: dadme lenguaje

Soy un antepasado golpeando un tronco hueco

estoy desnudo bajo la tormenta

Estoy solo en el bosque

85 sin otra compañía que la horda

A mi lado camina un reloj de pared

La materia total gira enloquece

Vienen los tigres que no se ven nunca

Y todo es solitario y sideral

90 Puedo escribir los versos más tristes esta noche
«Espiral», de Félix Grande: una letanía nerudiana para viajar por la historia 